\title{
SUSTENTABILIDADE NAS ORGANIZAÇÕES: O CASO DA EMPRESA DE PARTICIPAÇÕES E INVESTIMENTOS SUSTAINABILITY IN ORGANIZATIONS: THE CASE OF THE PARTICIPATION AND INVESTMENT COMPANY
}

\author{
Gilmar Carlos da Silva \\ Sílvio Roberto Stefano ${ }^{2}$ \\ Cláudio Luiz Chiusoli ${ }^{3}$
}

\section{Resumo}

A preocupação com o desenvolvimento sustentável e a sustentabilidade vai muito além dos cuidados com o meio ambiente, além do contexto histórico do desenvolvimento sustentável, relata uma perspectiva social mais abrangente, direitos humanos, questões de desenvolvimento social. O tema sustentabilidade vem se destacando não somente pela escassez de matéria-prima, mas também pela cobrança dos diversos públicos envolvidos, sejam eles clientes, fornecedores, funcionários e até mesmo o próprio governo; estes diversos públicos querem organizações focadas no objetivo socioambiental e a sua transparência quanto a suas ações para com assunto. $\mathrm{O}$ objetivo do artigo é, a partir dos relatórios anuais de uma empresa de participações e investimentos no período de 2012 a 2017, analisar a evolução do quadro de funcionários, números de acidentes, tempo de treinamento e investimentos em programas socioambientais dentro do contexto do desenvolvimento sustentável e sustentabilidade. A metodologia adotada foi uma análise documental por meio de um estudo de caso, verificando 6 relatórios anuais de sustentabilidade da empresa objeto do estudo, mediante verificação dos dados divulgados no site da organização. Os achados apontaram que a organização realizou investimentos em treinamentos e na diminuição da relação do número de acidentes.

Palavras-chave: Relatórios de Sustentabilidade. Programas Sustentáveis. Sustentabilidade. Desenvolvimento Sustentável. Sustentabilidade Organizacional.

1 Discente do Mestrado Profissional em Administração pela Universidade Estadual do Centro Oeste (UNICENTRO), Guarapuava, Paraná, Brasil. E-mail: gil.marg@ hotmail.com.

2 Doutor em Administração pela Faculdade de Economia, Administração e Contabilidade (FEA) da Universidade de São Paulo (USP). Docente do Mestrado Profissional em Administração (PPGADM) e do Mestrado e Doutorado Interdisciplinar em Desenvolvimento Comunitário (PPGDC) da Universidade Estadual do Centro Oeste (UNICENTRO), Guarapuava, Paraná, Brasil. E-mail: professorsilvio2013@gmail.com

3 Doutor em Administração pela Faculdade de Economia, Administração e Contabilidade (FEA) da Universidade de São Paulo (USP). Docente da Universidade Estadual do Centro Oeste (UNICENTRO), Guarapuava, Paraná, Brasil. E-mail: prof.claudio.unicentro@gmail.com 


\section{Abstract}

The concern for sustainable development and sustainability goes far beyond caring for the environment reports beyond the context of sustainable development history, a broader social perspective, human rights, social development issues. The sustainability theme has been highlighted not only by the scarcity of raw materials, but also by the collection of the various publics involved, whether they are customers, suppliers, employees and even the government itself, these various publics want organizations focused on the socio-environmental objective and also their transparency regarding their actions towards the subject. The objective of the article is, based on the annual reports of a participation and investment company from 2012 to 2017, to analyze the evolution of the staff, accident numbers, training time and investments in environmental partner programs within the context of sustainable development and sustainability. The methodology adopted was a documentary analysis through a case study, verifying 6 annual sustainability reports of the analyzed company, by verifying the data disclosed in the organization's website. The findings showed that the organization invested in training and in reducing the number of accidents.

Keywords: Sustainability Reports. Sustainable Programs. Sustainability. Sustainable Development. Sustainability in Organizations.

\section{INTRODUÇÃO}

Nos últimos trinta anos, os entendimentos de desenvolvimento sustentável foram se diversificando, e modos de pensar foram tomando diferentes rumos, alguns se completando e outras teorias se transformando em controversas. Desse modo, Stefano \& Teixeira (2014) entendem que o desenvolvimento sustentável é aquele que não compromete a sobrevivência de gerações futuras, por meio da exploração responsável de recursos naturais atualmente.

Já Gladwin, Kennelly \& Krause (1995) defendem a integração, sem danos, dos seres humanos ao ambiente, e define sustentabilidade como um estado econômico, de forma que as exigências impostas ao ambiente por pessoas e comércio têm que ser cumpridas sem reduzir a capacidade doambiente para prover as futuras gerações. Atitudes que no futuro não vão reduzir ou complicar a existência na terra, garantindo a perpetuidade do processo da vida, tentando ser o mínimo evasivo possível. Esses autores descrevem a importância da sustentabilidade, descrevendo-a como conectiva, pois os problemas do mundo devem ser compreendidos e são interconectados com ela. E que é algo de longo prazo e que somente será desenvolvido ao longo do tempo, e se colocadas de frente as crenças com os debates morais.

Atualmente, com a informação, se faz necessário escolher quais atitudes são as corretas com relação à sustentabilidade. Sabe-se que a natureza tem o poder de retribuir pelos maus-tratos exercidos sobre ela por meio dos tempos, e que cada ação deve ser pensada visando a continuidade da qualidade de vida na terra e das pessoas. (DINIZ; CALLADO, 2018).

Assim, há duas grandes correntes sobre os conceitos de desenvolvimento sustentável, envolvendo a perspectiva adotada em relação ao homem, considerando os sistemas técnicos, econômicos e sociais com a natureza. A primeira visão é da primazia do homem sobre a natureza, isto é, uma visão antropocêntrica; e a segunda é uma visão da natureza sobre o homem, uma visão biocêntrica. As duas correntes são visões polarizadas de mundo, embora dispostas em um mesmo continuum. (STEFANO; TEIXEIRA, 2014). 
Considerando essa perspectiva, a partir da década de 1990, as empresas começaram a divulgar seus relatórios ambientais com o objetivo de informar acerca do desempenho econômico, financeiro, social e ambiental das entidades aos diversos stakeholders. (RICARDO; BARCELLOS; BORTOLON, 2017).

Diante do exposto, o estudo se justifica devido à necessidade de, a partir do estudo dos relatórios anuais de uma empresa de participações e investimentos, compreender a relação entre as atitudes do homem com a natureza, que se delineiam a partir do conceito de que o desenvolvimento sustentável é algo amplo, que diz respeito a uma grande área ou região, e se norteiam em atitudes que interferem no modo de vida de toda uma população. (NOSSA; RODRIGUES; NOSSA, 2017).

A questão norteadora do estudo é: a partir dos relatórios anuais de uma empresa de participações e investimentos, como se dá a evolução do quadro de funcionários, números de acidentes, tempo de treinamento e investimentos em programas socioambientais dentro do contexto do desenvolvimento sustentável no período de 2012 a 2017? Portanto o objetivo do artigo é, a partir dos relatórios anuais de uma empresa de participações e investimentos, no período de 2012 a 2017, analisar a evolução do quadro de funcionários, números de acidentes, tempo de treinamento e investimentos em programas socioambientais dentro do contexto do desenvolvimento sustentável.

O presente artigo foi estruturado, inicialmente, pela introdução e, depois, com a apresentação dos conceitos teóricos; na sequência, apresenta os procedimentos metodológicos adotados para realizar a pesquisa. A seção seguinte refere-se às análises dos dados coletados e discriminação dos resultados obtidos; por fim, apresenta as considerações finais do estudo.

\section{FUNDAMENTAÇÃO TEÓRICA}

Neste capítulo, serão abordados aspectos relacionados ao desenvolvimento sustentável, sustentabilidade empresarial e responsabilidade socioambiental.

\subsection{Desenvolvimento sustentável e sustentabilidade organizacional}

O desenvolvimento sustentável deixou de ser algo opcional no decorrer dos anos. Hopwood, Mellor \& Geoff (2005) descrevem que, embora reconheçam os profundos debates e ambiguidades sobre o significado do desenvolvimento sustentável, utilizam a expressão desenvolvimento sustentável para descrever as tentativas de combinar preocupações com o meio ambiente e as questões socioeconômicas.

O tema é amplo e, muitas vezes, possui pontos de vista contraditórios, mas que são combinações que tentam aliar as questões socioeconômicas com o meio ambiente, pois de nada adianta garantir o sucesso econômico, se for para deteriorar ou comprometer o meio ambiente; isso seria destruir o nosso próprio futuro.

Segundo Hopwood, Mellor \& Geoff (2005), o desenvolvimento sustentável se identifica com o crescimento econômico e é visto como parte da solução dos problemas do desenvolvimento, pois de nada adianta pensar somente no meio ambiente, sabendo que a população está crescendo e que é necessário manter o processo evolutivo; e o mesmo se aplica ao contrário, de nada adianta pensarmos somente no crescimento econômico, se comprometermos a continuidade de nossa espécie na terra.

Segundo Gladwin, Kennelly \& Krause (1995), o desenvolvimento sustentável é entendido como um conjunto de ações de: i) inclusão, ii) integração, iii) igualdade, iv) prudência e v) segurança. Para os autores, a inclusão sugere o desenvolvimento humano, já a integração reconhece a existência de uma interdependência entre os domínios ecológicos, sociais e econômicos. Por outro lado, a igualdade busca a justiça intergeracional, intrageracional e interespécies; enquanto a prudência investiga os 
meios de cuidados e prevenção em referência aos atos tecnológicos, científicos e políticos. E, por fim, a segurança, uma proteção contra ameaças crônicas e contra acontecimentos nocivos.

Nesse sentido, Pazini et al (2019) apontam que o desenvolvimento sustentável está configurado em vantagem competitiva às organizações, onde ações e objetivos estratégicos podem angariar novos mercados, novos clientes e, logicamente, aumentar a lucratividade de maneira sustentável.

A ideia de que somente quando há crescimento econômico é que se pode pensar em despender uma parte do lucro para as boas ações é defendida no status quo, e realmente, na maioria dos casos, é isso o que acontece. As pequenas empresas só se preocupam com o meio ambiente a partir do momento em que, de certa forma, o governo as obriga a se adequarem em troca de algum benefício; e as grandes empresas também destinam uma parte de seus lucros visando deduções de impostos, ou até mesmo a criação de uma imagem para a própria empresa, buscando uma melhor aceitação da população. (AMARAL; STEFANO; CHIUSOLI; 2018). Para Sachs (2008), o crescimento deve ser puxado pelo emprego, os investimentos devem ser concentrados nos pequenos e menos desprovidos, seja na cidade ou na zona rural, e quando a sociedade evolui, se ela está pareada com o desenvolvimento sustentável, todo mundo ganha.

Nesse sentido, houve grandes mudanças, principalmente no quesito de informação, onde o tema sustentabilidade já tem uma linha de pensamento a ser seguida, mesmo sendo um tema amplo e com muitas situações a serem definidas para a sua melhoria. A expressão sustentabilidade é tema de muitas discussões, no meio acadêmico e no ambiente organizacional, e tem despertado para os problemas de impactos ambientais em relação à atividade de empresas produtoras ou prestadoras de serviços. (VALADÃO JÚNIOR et al, 2017).

Para Elkington (2012), sustentabilidade é uma nova forma de religião, uma última aberração da alma humana no século 20; já para Blowfield (2013), há sérios desafios de sustentabilidade e são um risco inerente aos negócios por causa da incerteza que causam. As empresas continuam tratando o tema como um entrave que só traz prejuízos financeiros, mas que ao mesmo tempo, por pressões de ONGS e da sociedade é algo a ser repensado.

Para Elkington (2012), o cérebro empresarial continua esperando que os desafios ambientais e sociais desapareçam, todavia eles ressurgem mais profundos e fortes; ou seja, o lucro, a situação econômica sempre fala mais alto, sendo que as empresas, quase que em sua totalidade, consideram a sustentabilidade como um último plano, em casos específicos em que há sucesso no negócio. Mas como é um tema que está na mídia, podemos trazer para os dias atuais e tentar entender como seria o processo de implantação de um sistema de sustentabilidade.

Em qualquer tipo de mudança, o início da implementação é sempre árduo e requer muito esforço por parte da organização, na questão da sustentabilidade não é diferente. Enquanto a sustentabilidade refere-se à capacidade de manter algo em um estado contínuo, o desenvolvimento sustentável envolve processos integrativos que buscam manter o balanço dinâmico e a continuidade de todo esse processo, sendo uma questão de sobrevivência no mercado, e não mais algo opcional. (MUNCK; BANSI; GALLELI-DIAS; CELLA-DE-OLIVEIRA, 2013; AMARAL; STEFANO; CHIUSOLI, 2018).

Para iniciar esse processo de implantação é necessário que seja verificado o que há disponível de estudos relacionados ao tema. Ao iniciar com Quental, Lourenço \& Silva (2011), a identificação de princípios de sustentabilidade é, possivelmente, mais interessante do que fornecer uma definição rígida, que são mais abstratos e conceituais. Não há um conceito rígido que se aplique em qualquer empresa, por isso os autores elencam princípios para essa implantação.

Com a proposta de alcançar a sustentabilidade, outra importante questão a ser considerada é como mensurá-la. Mesmo que não esteja muito claro o critério de avaliação, a performance do 
indicador ambiental é sugerida, em vários estudos, como um aspecto importante para mensurar a sustentabilidade. (LEE, 2012). Essa questão de delimitações e tentativas de se chegar a algo mais próximo da realidade de todas as empresas podem guiar e ter referências maleáveis, de forma que cada autor tenta facilitar o processo de implantação. Nesse sentido, Blowfield (2013) identifica três áreas principais de sustentabilidade: demográfica (mudanças no tamanho e nos padrões da população); ecossistemas (luz do sol, água e organismos vivos); e mudanças climáticas.

Também complementando tem-se que os quatro principais princípios da sustentabilidade foram identificados, segundo Quental, Lourenço \& Silva (2011) como:

i) Princípio dos limites: dentro da ecosfera, a sustentabilidade depende de garantir que a escala da economia humana seja baixa o suficiente para permitir a manutenção dos sistemas saudáveis de suporte à vida;

ii) Princípio dos meios e finais: o crescimento econômico não é entendido como um fim em si, e sim como um instrumento que pode ajudar a alcançar fins de ordem superior, como bem-estar humano e liberdade;

iii) Princípio das necessidades: necessidades irredutíveis devem ser satisfeitas independentemente e não podem ser agregadas;

iv) Princípio da complexidade: sistemas socioecológicos são complexos e têm múltiplos equilíbrios estáveis.

Essa tentativa de reduzir um tema amplo como a sustentabilidade organizacional em microtemas (princípios) deve-se a sua complexidade, pois há dúvidas até mesmo sobre o que deve ser sustentado, em que tempo e com que interesse. E em épocas em que tudo muda com tanta velocidade, Munck, Bansi, Galleli-Dias \& Cella-de-Oliveira (2013) citam que tanto a organização quanto a sustentabilidade organizacional são processos que existirão e estarão em mudança por meio da variável tempo, nesse sentido dependerão de indivíduos ativos revendo periodicamente o processo. Ou seja, em qualquer patamar que a organização se encontre, as mudanças ocorrem a cada minuto, e a complexidade só aumenta, e o tempo deve ser utilizado a favor no momento de iniciar a mudança, para que faça efeito e sejam colhidos os frutos.

Para Quental, Lourenço \& Silva (2011), as substâncias produzidas pela sociedade não devem aumentar sistematicamente na ecosfera; a base física para a produtividade e diversidade da natureza não deve ser sistematicamente deteriorada; é necessário um uso justo e eficiente dos recursos em relação à reunião das necessidades humanas. Esse pensamento sustentável por parte das organizações deve ter cunho social, não acima do lucro, mas pelo menos que o acompanhe lado a lado para que juntos possam ser exaltados e sempre focados, indiferentemente de qual ramo a empresa exerça.

Nesse sentido, de acordo com Munck, Bansi, Galleli-Dias \& Cella-de-Oliveira (2013, p.23), a sustentabilidade organizacional "não deve ser trabalhada como um projeto a parte, demandante de esforções específicos, muito pelo contrário, deve integrar os processos organizacionais tendo os indivíduos como atores centrais neste caminho". Foco no capital humano, em quem pode mudar a visão da empresa e garantir um futuro melhor.

Essa preocupação com o futuro, que iniciou com a revolução industrial, até hoje segue a mesma visão do medo e também do comprometimento; assim, Quental, Lourenço \& Silva (2011) descrevem que a sustentabilidade considera que a escala da economia humana não deve exceder a capacidade de transporte do meio ambiente e não pode degradar os recursos finitos.

Seguindo a linha de tentativas de modelos de aplicação, Munck (2013) descreve três dimensões da sustentabilidade: sustentabilidade econômica (fluxo de caixa garantido em qualquer tempo), sustentabilidade social (utilização dos recursos naturais apenas em quantidades proporcionais à reprodução natural) e sustentabilidade ambiental (agregar valor para as comunidades as quais estão 
inseridas). Para o autor, ao analisar os cinco modelos de gestão da sustentabilidade (dois são do Reino Unido, um da Noruega, um da Itália e um do Brasil), identificou-se que a maioria se baseia na perspectiva do Triple Bottom Line (TBL), o que reforça o fato de esta ser uma teoria stream quando se trata de sustentabilidade nas organizações.

Munck, Bansi, Galleli-Dias \& Cella-de-Oliveira (2013) remetem a opção de converter os pilares da sustentabilidade organizacional em três sustentabilidades: organizacional econômica, organizacional ambiental e organizacional social. Assim, Elkington (2012) destaca que os três pilares da sustentabilidade se tornam então sustentadores e viabilizadores da sustentabilidade organizacional. Cada autor trata da situação ampla e elege fases que podem contribuir para o desenvolvimento de outras empresas que estão em busca desse objetivo.

O termo sustentabilidade incorpora-se como um progresso organizacional no longo prazo com o objetivo de alcançar a competência econômica, ambiental e social respectivamente, cujo progresso determina que as empresas desenvolvam novas capacidades e ações estratégicas para incorporar as cobranças ambientais. (WU; HE; DUAN, 2013).

Munck, Bansi, Galleli-Dias \& Cella-de-Oliveira (2013) complementam que a partir da constatação de que as ações organizacionais não devem ser consideradas sustentáveis quando atenderem, ainda que eficientemente, a apenas um ou outro pilar da sustentabilidade, emerge a necessidade de integrá-los. Ou seja, verificados todos os pilares, todas as situações em que as empresas devem pensar, pode-se concluir que são vastos os itens a serem aplicados, e que o atendimento a apenas um deles não pode ser levado em consideração caso seja o único foco da empresa e não esteja em contribuição aos demais.

Nesse contexto, é necessário considerar o agir organizacional, que seria a parte principal da organização, as suas atitudes. Cada decisão de uma empresa tem uma reação dentro dela e na sociedade. Neste caso, Munck, Bansi, Galleli-Dias \& Cella-de-Oliveira (2013) podem contribuir, pois descrevem que este agir organizacional é composto por um processo de ações e decisões, dotado de racionalidade intencional e limitado; já para Munck (2013), o agir organizacional concerne tanto aos processos de ação de um sujeito singular quanto aos processos de ação coletiva, deve ser revisto e impresso no sangue da organização para que tenha seus efeitos paralelos com a sustentabilidade organizacional.

Para que possam ser sustentáveis, essas regras devem atender tanto ao objetivo das organizações como também ao objetivo da sociedade. Então, Lee (2012) descreve que o agir organizacional ordena as ações do processo em direção a um objetivo perseguido, mas esse agir organizacional é intencional e limitado, assim como a razão humana o é, de forma que há concordâncias entre esses autores sobre a importância da ação organizacional nesse processo.

Galleli \& Hourneaux (2019) apontam que as organizações que utilizam a gestão para comunicar e disseminar as implementações de sustentabilidade podem ter maior rentabilidade com o desenvolvimento sustentável, como identificar competência sustentável em seus gestores e funcionários de toda a organização.

Há muitas pessoas que veem a sustentabilidade essencialmente como uma jogada de investimento, pois seu interesse é substituir um conjunto de tecnologias, aquelas associadas a altos níveis de emissões de carbono, por um conjunto alternativo. Outras pessoas veem que os desafios da sustentabilidade são mais profundos do que as tecnologias de transformação, não apenas se a mudança é alcançável, mas se é desejável, segundo Blowfield (2013).

Essa jogada de investimento já é realidade, devido ao comprometimento com o meio ambiente e por questões de pressão impostas pelos próprios clientes, que querem adquirir produtos que não tenham efeitos negativos para sua própria vida. Em contrapartida, temos os empresários, que segundo Blowfield (2013) também apontam que não estão livres para agir como querem quando se trata de sustentabilidade. 
O tema é amplo e complexo e, como Elkington (2012) descreve, a crise de sustentabilidade se tornará ainda pior antes de termos alguma expectativa de dobrar a esquina.

\subsection{Responsabilidade socioambiental}

Internamente, nas empresas, e posteriormente no agir organizacional, alguns itens devem ter foco especial e ser rigorosamente verificados. A justiça socioambiental é um deles. A justiça socioambiental não requer, por exemplo, que um trabalhador do chão de fábrica trabalhe em uma sala igual à do presidente da organização. Na realidade, a luta reside em que todos tenham direito a respirar um ar de mesma qualidade, trabalhar em níveis de temperatura e de ruído não prejudiciais à saúde e confortáveis, isto é, defende-se que todos compartilhem dos benefícios e malefícios das atividades organizacionais. (MUNCK; BANSI; GALLELI-DIAS; CELLA-DE-OLIVEIRA, 2013).

A igualdade deve ser verificada, para fins de melhorias mútuas; contudo, sabe-se que isso é algo fora da realidade no momento, o que pode ser feito é minimizar as diferenças ao longo do tempo. Munck (2013) nos indica as empresas consideradas líderes no trabalho com as questões ambientais não subestimaram o potencial de transformar a sustentabilidade em uma vantagem competitiva. E, também, em um diferencial na vida de seus funcionários.

É necessário que as empresas deixem de lado a velha ideia de que a sustentabilidade é um custo, por ainda não apresentar vantagens claras, pois conforme Elkington (2012), para cada fatalidade, cada perdedor, existem dúzias de potenciais vencedores. Ainda Blowfield (2013) descreve que a sustentabilidade pode ser vista como o mais recente exemplo de mudança profunda, que exige transformação em toda a sociedade e, principalmente, na mentalidade humana, de acreditar que é possível.

Para Dias (2011), as empresas são responsáveis indiretamente pelo crescimento do interesse pelo meio ambiente, tendo em vista que foram as causadoras dos principais desastres ambientais do século $\mathrm{XX}$, os quais, de certa forma, despertaram a consciência coletiva para estes problemas ambientais. Todo desastre ambiental, quando envolve determinada organização, geralmente traz à tona tudo aquilo que ela fez de errado ou deixou de fazer, e isso sempre causa um enorme alvoroço na sociedade, que crucifica a organização causadora. É neste sentido que as organizações têm se protegido, implantado estratégias para que não sejam alvo dessas situações, o que pode ser considerado algo individualista, pois a organização não pensa em diminuir os impactos ambientais, e sim em desviar-se de problemas com a justiça. Dias (2011) descreve que quanto maior a organização, maior é a pressão exercida sobre ela com relação à sustentabilidade socioambiental, e isso vem, inclusive, por parte de seus clientes que, muitas vezes, são de países desenvolvidos, onde as exigências ambientais são maiores.

Para Barbieri (2007), espera-se que as empresas deixem de ser problemas e façam parte das soluções. A sociedade já deposita a sua confiança sobre as organizações e já conta, com sua participação, visto que sabem que as empresas têm o poder de contribuir muito para a sustentabilidade social e ambiental. Ainda, o autor elenca que as preocupações ambientais são influenciadas por três grandes conjuntos de forças que interagem reciprocamente: o governo, a sociedade e o mercado. O governo elabora leis que obrigam as empresas a respeitá-las, sendo ameaçadas por altas multas; a sociedade efetua elevada pressão por se dizer dependente do processo; e o mercado, que para atender aos desejos da sociedade, também elabora suas próprias regras.

Para Dias (2012), as mudanças e as transformações envolvem todas as formas de empresas, e isso cria uma cidadania corporativa, que elege a empresa como um agente decisivo para a configuração da sociedade, tendo em vista que em qualquer ramo de atividade a empresa está sujeita a essas responsabilidades impostas pelo governo, sociedade e clientes. $\mathrm{O}$ autor cita que responsabilidade 
social constitui uma forma de gestão da empresa, a qual implica na sua colaboração com a sociedade, incorporando as preocupações desta como parte de sua estratégia de negócios.

A estratégia de negócios deve ser alinhada com a responsabilidade socioambiental, enraizada na organização, para que cada decisão seja tomada baseada na sustentabilidade, e somente assim os planos se alinham para que o futuro seja garantido sem comprometer o meio ambiente e a sociedade. Tais ações corroboram uma aproximação às preocupações sociais e ambientais. (AMEER; OTHMAN, 2017).

\section{PROCEDIMENTOS METODOLÓGICOS}

De acordo com Cooper \& Schindler (2003) a pesquisa em administração é uma investigação sistemática que provê informações para orientar as decisões empresariais, reforçando em um ponto que a pesquisa tem uma ênfase prática na solução de problemas, quer seja para correção, quer seja para oportunidade. Para tanto, os procedimentos metodológicos enquadram-se na categoria de pesquisa documental, mediante um estudo de caso descritivo, que se caracteriza por ser utilizada para descrição de características de indivíduos, grupos, organizações e comunidades e pode também ser utilizada para descrever a ocorrência de fenômenos. (MARCONI; LAKATOS, 2010; GIL, 2009).

Godoy (2005) esclarece que a análise de documentos traz importantes contribuições para a pesquisa, uma forma de complementar e checar os dados compilados. Por intermédio dos documentos coletados, avalia-se os contextos particulares em que a empresa se relaciona com a problemática e objeto da investigação. Diante dessa coleta de características, tem-se a possibilidade de efetuar uma análise de como realmente funcionam os fatos no dia a dia da organização.

No estudo, foram analisados 6 relatórios anuais de sustentabilidade de uma empresa de participações e investimentos, dos anos de 2012 a 2017, divulgados no site da organização, os quais apresentam informações e permitem a análise para o atingimento do objetivo do trabalho. As informações disponíveis foram analisadas a fim de compreender sua missão, visão e valores (Quadro 1), a evolução do número de funcionários (Quadro 2), a evolução do número de acidentes de trabalho (Quadro 3), a evolução do tempo de treinamentos em horas (Quadro 4), e os investimentos em programas socioambientais (Quadro 5).

Para justificar a escolha da empresa, trata-se de uma organização entre as principais do setor de infraestrutura no Brasil, a qual oferece serviços nos segmentos de concessão rodoviária, administração de aeroportos, administração portuária, cabotagem, geração de energia, além de usinas de asfalto, pedreiras, concreteiras, extração e venda de areia. Possui mais de 5 mil funcionários trabalhando entre as suas mais de 10 unidades. Segundo informações disponibilizadas em seu site, a empresa iniciou suas operações em 1999 no setor de rodovias, em 2005 começou a construção do primeiro porto privado do país, em 2010 ampliou os seus negócios para o setor de energia, iniciou no setor de cabotagem em 2011, e em 2012 venceu uma concessão para administrar um aeroporto do país.

\section{RESULTADOS E DISCUSSÃO}

A partir desse tópico a análise dos resultados se dará referente a cinco quesitos investigados, os quais tratam das seguintes informações: missão, visão e valores (Quadro 1), evolução do número de funcionários (Quadro 2), evolução do número de acidentes de trabalho (Quadro 3), evolução do tempo de treinamentos em horas (Quadro 4) e investimentos em programas socioambientais (Quadro 5).

Dessa forma, reitera-se que a empresa investigada disponibiliza os seus relatórios na internet para que toda a população possa ter acesso e verificar o que está acontecendo dentro e fora da organização de forma mais transparente. No relatório, a empresa afirma que se preocupa com o ambiente em que 
está inserida, possuindo várias ações de preservação, e, também, de cuidados de seus funcionários, reconhecendo a importância deles em todas as suas ações. Por isso investe constantemente no desenvolvimento e na transformação de potencial de seus profissionais.

A empresa possui missão, visão e valores, e é a partir dessa base que toma todas as suas decisões, norteada por princípios enraizados e que a destinam para um futuro condizente. Ter claro a missão, visão e valores é ter a identidade organizacional aplicada, onde todos os funcionários devem conhecer e aplicar seus conhecimentos sempre se baseando nelas.

A missão, visão e valores da empresa podem ser verificados no Quadro 1, o qual, ao descrever a missão a empresa, está delimitando como é o seu trabalho, juntamente com a visão, que é onde a empresa quer chegar, isso representa o presente e o futuro; e, para completar, são descritos os Valores, que são os princípios, ou seja, algo do passado que esta intrínseco a organização. Assim, segundo Stefano e Teixeira (2014), a preocupação da gestão vem buscar alternativas de negócios que gerem retorno e, ao mesmo tempo, benefícios à sociedade.

Quadro 1 - Missão, Visão e Valores

\begin{tabular}{|l|l|}
\hline Missão & $\begin{array}{l}\text { Prover serviços públicos de infraestrutura diferenciados e de qualidade, satisfazendo nossos } \\
\text { clientes e tornando-se, assim, a companhia mais valorizada do mercado neste segmento de } \\
\text { atuação. }\end{array}$ \\
\hline Visão & $\begin{array}{l}\text { Ser referência no mercado de serviços de infraestrutura, tendo como filosofia a inovação e o } \\
\text { pioneirismo. }\end{array}$ \\
\hline Valores & $\begin{array}{l}\text { Respeito ao ser humano } \\
\text { Respeito ao meio ambiente } \\
\text { Apoio as comunidades onde estamos inseridos } \\
\text { Inovação } \\
\text { Ética } \\
\text { Qualidade } \\
\text { Transparência } \\
\text { Tecnologia }\end{array}$ \\
\hline
\end{tabular}

Fonte: dados da empresa no site (2017).

Ainda, a empresa, em seus relatórios, torna público várias informações para que a população saiba o que acontece nela. A transparência é um dos objetivos da organização. A primeira comparação efetuada diz respeito ao seu quadro de funcionários, conforme a Quadro 2.

Observa-se que desde 2012 houve um aumento crescente do número de funcionários, até 2016, tendo uma redução em 2017 somente; a mesma situação se repete quando se analisa o número de mulheres. Porém, ao inserir a \% de mulheres, observa-se que em $201231 \%$ do quadro funcional era representado pelas mulheres, mas no ano subsequente, em 2013, esse índice diminui para $28 \%$, e se manteve também em 2014; a partir de 2014, até 2017, a porcentagem de mulheres começou a subir gradativamente, alcançando 35\%. Em 2015, esses dados não estavam disponíveis.

O número de mulheres trabalhando e ocupando seus cargos em empresas é muito importante para que ocorra a igualdade social; porém as mulheres continuam sendo a minoria, como mostram os números do Quadro 2; os homens continuam sendo predominantes, até porque o trabalho no recape e reparação das rodovias sob concessão emprega mais esse perfil de mão de obra (média de $70 \%$ ), principalmente devido à capacitação, mas esta é uma tendência que deve ser mudada, visto que homens e mulheres possuem as mesmas condições.

Tal posição reforça a crescente participação feminina em outros ambientes de trabalho, o que antes era mais restrito aos ambientes domésticos e rurais e, com o passar dos tempos, a mão de obra 
foi, pouco a pouco, se interessando pelo trabalho no meio assalariado e ocupando várias posições de comando. (OLIVEIRA; OLIVEIRA, 2019). A seguir apresenta-se o Quadro 2 com a evolução do número de funcionários na organização no período de 2012 a 2017.

Quadro 2 - Evolução do número de funcionários versus gênero

\begin{tabular}{|l|c|c|c|c|c|c|}
\hline ITEM & $\mathbf{2 0 1 2}$ & $\mathbf{2 0 1 3}$ & $\mathbf{2 0 1 4}$ & $\mathbf{2 0 1 5}$ & $\mathbf{2 0 1 6}$ & $\mathbf{2 0 1 7}$ \\
\hline Número de funcionários & 3092 & 3428 & 4369 & 5491 & 5650 & 4267 \\
\hline Mulheres & 958 & 974 & 1215 & $\mathrm{X}$ & 1808 & 1461 \\
\hline \% Mulheres & $31 \%$ & $28 \%$ & $28 \%$ & $\mathrm{X}$ & $32 \%$ & $35 \%$ \\
\hline Homens & 2134 & 2454 & 3154 & $\mathrm{X}$ & 3842 & 2806 \\
\hline$\%$ Homens & $69 \%$ & $72 \%$ & $72 \%$ & $\mathrm{X}$ & $68 \%$ & $65 \%$ \\
\hline
\end{tabular}

Fonte: dados da empresa no site (2017).

Outro item analisado foi em relação ao número de acidente de trabalho. Conforme o Quadro 3, o ano de 2012 foi o único em que não foi citada a quantidade de acidentes de trabalho, e se pode deduzir que mesmo o número de funcionários tendo aumentado sequencialmente de 2012 até 2016, os números absolutos de acidentes não acompanham esse crescimento proporcionalmente. Entre $2013 \mathrm{e}$ 2014 houve um aumento no número de acidentes, em 2015 houve uma diminuição, em 2016 aumentou novamente, e em 2017 teve o menor número de acidentes de todos os relatórios analisados. No entanto, em 2017, a porcentagem dos acidentes em relação ao número de funcionários ficou em torno de 2,8\%.

Os acidentes de trabalho são um indício de que algo precisa ser melhorado. Esse indicador precisa ser melhorado ano a ano, pois os acidentes, além de causar danos à saúde física do colaborador, muitas vezes ocasionam o seu afastamento, o que compromete a produção.

Os dados sugerem, pelas características na operação das unidades da empresa investigada, a qual trabalha com construção e material pesado, que o maior índice de acidentes deve ocorrer entre os funcionários do gênero masculino. De acordo com os dados da previdência Social, analisados pelo Observatório de Segurança e Saúde no Trabalho, foram gastos em todo o país cerca de R 79 bilhões, entre 2012 e 2018, em benefícios de natureza acidentária pagas aos segurados ou dependentes. (CARVALHO; CRUZ, 2019).

Quadro 3 - Evolução do número de funcionários versus acidentes de trabalho

\begin{tabular}{|l|c|c|c|c|c|c|}
\hline ITEM & $\mathbf{2 0 1 2}$ & $\mathbf{2 0 1 3}$ & $\mathbf{2 0 1 4}$ & $\mathbf{2 0 1 5}$ & $\mathbf{2 0 1 6}$ & $\mathbf{2 0 1 7}$ \\
\hline Número de funcionários & 3092 & 3428 & 4369 & 5491 & 5650 & 4267 \\
\hline Acidentes & $\mathrm{X}$ & 144 & 149 & 135 & 167 & 119 \\
\hline$\%$ Acidentes por colaborador & $\mathrm{X}$ & $4,2 \%$ & $3,4 \%$ & $2,5 \%$ & $3,0 \%$ & $2,8 \%$ \\
\hline
\end{tabular}

Fonte: dados da empresa no site (2017).

Outra informação disponibilizada diz respeito ao investimento nas horas de treinamento na organização, representadas na Quadro 4. Observa-se que em apenas três relatórios, de 2013 a 2015, por algum motivo não esclarecido, a empresa não divulgou esta informação; verifica-se também que este investimento vem apenas diminuindo a cada ano que passa, e em proporções razoáveis, sendo reduzido mais da metade a cada ano analisado. Ou seja, de 380 mil horas em 2012, em 2017 foram somente 79 mil horas de treinamento.

Os treinamentos são muito importantes, pois são um investimento no capital humano que retorna para a organização em forma de redução de acidentes, de melhor aproveitamento da matéria-prima, e tudo isso sinaliza uma grande melhoria no lucro da organização. (ARAUJO; ABBAD; FREITAS, 2017). 
Quadro 4 - Evolução do número de funcionários versus tempo de treinamentos

\begin{tabular}{|l|c|c|c|c|c|c|}
\hline ITEM & $\mathbf{2 0 1 2}$ & $\mathbf{2 0 1 3}$ & $\mathbf{2 0 1 4}$ & $\mathbf{2 0 1 5}$ & $\mathbf{2 0 1 6}$ & $\mathbf{2 0 1 7}$ \\
\hline Número de funcionários & 3092 & 3428 & 4369 & 5491 & 5650 & 4267 \\
\hline Horas de treinamento (mil) & 380.000 & ND & ND & ND & 179.000 & 79.000 \\
\hline Média de horas / colaborador & 123 horas & ND & ND & ND & 32 horas & 18 horas \\
\hline
\end{tabular}

Fonte: dados da empresa no site (2017). ND: não disponível

Com relação aos investimentos socioambientais, tem-se que no Quadro 5 os valores aplicados nestes programas. Verifica-se que houve investimentos relativamente altos em 2013 e em 2016, não se pode afirmar os motivos, devido ao não esclarecimento no relatório; da mesma forma, as áreas de conservação são destacadas somente nos anos de 2012 e 2013.

Por outro lado, a empresa possui vários programas e afirma em todos os seus relatórios a defesa do meio ambiente, focada em reduzir os impactos ambientais gerados pela sua atividade. Em 2017, em seu relatório, ela descreve a seguinte situação, provavelmente em função das atividades exercidas, pois trabalha com extração de areia e outras atividades que podem gerar tal impacto: "conformidade e transparência, uso racional dos recursos naturais, gestão de riscos, melhoria contínua, atenção às mudanças climáticas e responsabilidade compartilhada".

Ainda, a empresa possui um instituto que atende vários programas, sendo eles: educação para o trânsito, Operação inverno, um freio a fome, guarda parque mirim, futebol de rua, programa na mão certa, museu rodoviário.

Dias (2011) descreve que as empresas estão sendo cada vez mais solicitadas a assumirem maiores responsabilidades, quando se trata da manutenção da qualidade de vida, pois elas são um dos principais responsáveis pelos problemas ambientais, onde seu planejamento estratégico não pode mais deixar de lado essa questão ambiental.

Quadro 5 - Investimentos em programas socioambientais (SA)

\begin{tabular}{|l|c|c|c|c|c|c|}
\hline ITEM & $\mathbf{2 0 1 2}$ & $\mathbf{2 0 1 3}$ & $\mathbf{2 0 1 4}$ & $\mathbf{2 0 1 5}$ & $\mathbf{2 0 1 6}$ & $\mathbf{2 0 1 7}$ \\
\hline Investimento sócio ambiental (milhões) & 1,6 & 36,6 & ND & 3,7 & 32,7 & 1,8 \\
\hline Áreas de conservação $\left(\mathrm{km}^{2}\right)$ & 20,9 & 25,1 & ND & ND & ND & ND \\
\hline
\end{tabular}

Fonte: dados da empresa no site (2017). ND: não disponível

O quadro 5 apresenta-se os investimentos em programas SA de 2012 a 2017, observa-se que em alguns anos houve maiores investimentos por exigências legais como Ibama e Ministério do Trabalho. A seguir, apresenta-se as considerações finais do estudo com suas contribuições, limitações e apontamentos para estudos futuros.

\section{CONSIDERAÇÕES FINAIS}

O objetivo do artigo foi analisar, a partir dos relatórios anuais no período de 2012 a 2017, a evolução do quadro de funcionários, números de acidentes, tempo de treinamento e investimentos em programas socioambientais dentro do contexto do desenvolvimento sustentável.

Aspectos limitantes observados foram alguns dados incompletos nos relatórios, bem como os resultados sugerem que não há uma regularidade dos itens quando comparados aos relatórios de sustentabilidade disponibilizados no site da empresa investigada. Pode-se destacar como aspectos positivos que há disponibilidade de investimentos em várias áreas da sustentabilidade, independentemente da situação conjuntural do país. 
Destaca-se, através desse estudo e dos autores verificados, que há uma gama de possibilidades para sustentabilidade a serem implantadas nas organizações, e que a soma de cada atitude pode sim transformar o mundo em que se vive a partir de decisões empresariais, levando em consideração cada contribuição dos estudiosos da área e unindo a força de vontade do agir organizacional aqui tratado.

A dificuldade existe, e sempre existirá, pois assim como tudo muda em questão de segundos, a sustentabilidade também muda; fazendo a junção entre ações rápidas, implementações subsequentes, e um controle efetivo, no futuro haverá grandes melhorias e, principalmente, se o desejo e a capacidade de enfrentar essas mudanças forem efetivas, nada será considerado como contrário.

A empresa objeto do estudo sugere que tem preocupação com o meio ambiente, e também tem a proposta de expor de forma transparente o que acontece na organização; mesmo durante os períodos de crise houve investimentos em meio ambiente e em seus funcionários, demonstrando respeito tanto com o meio ambiente quando com seus funcionários; são várias as atividades e investimentos propostos pela empresa, e que atingem não somente os funcionários da organização, mas também a comunidade em geral, compartilhando as boas ações e contribuindo para uma sociedade melhor e mais sustentável.

Como achados nos relatórios destaca-se que a proporção de mulheres na empresa aumentou para 35\% em 2017, mesmo considerando que, em essência, a atividade da empresa era voltada ao perfil masculino. Que o índice de acidente de trabalho em relação ao número de funcionários demonstrou leve queda, passando de 4,5\% em 2013, para 2,8\% em 2017; embora tenha ficado evidente que a quantidades média de horas de treinamento por colaborador teve uma queda substancial de 123 horas em 2012 para 18 horas em 2017. E por fim, o valor investido em programas socioambientais tem oscilado de um ano para outro, muito embora o relatório não destaque os motivos.

A contribuição da pesquisa foi de demonstrar o estudo sobre desenvolvimento sustentável, a respeito da importância de disponibilizar por meio dos relatórios anuais as informações da organização, levando a uma melhor imagem da mesma e, consequentemente, o fortalecimento de sua legitimidade.

A limitação da pesquisa é devido ser baseada apenas em informações disponibilizadas no site da instituição e em uma única empresa do setor. Bem como, o fato de que algumas informações estavam incompletas e não havia esclarecimentos suficientes sobre algum dado, apesar de que alguns dados poderiam ser efetuados solicitando informações extras diretamente a organização ou por meio de entrevista.

Como sugestão de trabalho futuro, seria revisar e acompanhar os dados subsequentes dos relatórios dos anos de 2018 em diante para verificar se há padronização das informações conforme relatórios anteriores. Da mesma forma, seria interessante acompanhar relatórios de outras empresas do setor para efeito de comparação.

\section{REFERÊNCIAS}

AMARAL, L. A.; STEFANO, S. R.; CHIUSOLI, C. L. Sustentabilidade organizacional na perspectiva do triple bottom line: o caso Itaipu binacional. Recc - Revista Eletrônica Científica do CRA-PR, Curitiba, PR, v. 5, n.1, p.52-68, set. 2018.

AMEER, R.; OTHMAN, R. Corporate social responsibility performance communication and portfolio management. Managerial Finance, Patrington, v. 43, n. 5, p. 595-613, 2017.

ARAUJO, Maria Cecília dos Santos Queiroz de; ABBAD, Gardênia da Silva; FREITAS, Thais Rodrigues de. Avaliação qualitativa de treinamento. Revista psicologia organizações e trabalho, Brasília, DF, v. 17, n. 3, p. 171-179, set. 2017. 
BARBIERI, J. C. Gestão ambiental empresarial: conceitos, modelos e instrumentos. 2. ed. São Paulo: Saraiva, 2007.

BLOWFIELD, M. Business and sustainability. Oxford: UK, 2013.

COOPER, D. R.; SCHINDLER, P. S. Métodos de pesquisa em administração. 7. ed. Porto Alegre: Bookman, 2003.

CARVALHO, Sarah Araújo; CRUZ, Pedro Henrique Maglioni. Análise longitudinal dos acidentes de trabalho no estado de Santa Catarina entre os anos de 2012 e 2017 por meio de método de séries temporais. Revista da Escola Nacional da Inspeção do Trabalho, Brasília, DF, ano 3, 2019.

DIAS, Reinaldo. Gestão ambiental: responsabilidade social e sustentabilidade. 2. ed. São Paulo: Atlas, 2011.

. Responsabilidade social: fundamentos e gestão. São Paulo: Atlas, 2012.

DINIZ, Maria Luiza Farias; CALLADO, Aldo Leonardo Cunha. Mensurando a sustentabilidade empresarial através do grid de sustentabilidade empresarial (GSE): um estudo em empresas do setor gráfico. Amazônia, Organizações e Sustentabilidade, Belém, PA, v. 6, n. 2, p. 105-122, 2018.

ELKINGTON, J. Canibais com garfo e faca. São Paulo: Makron, 2012.

GALLELI, B.; HOURNEAUX JUNIOR, F. Human competences for sustainable strategic management: evidence from Brazil. Benchmarking: An International Journal, v.26, n.2, 2019.

GIL, A. C. Estudo de caso. São Paulo: Atlas, 2009.

GLADWIN, T. N., KENNELLY, J. J.; KRAUSE, T. S. Shifting paradigms for sustainable development. Academy of Management, New York, v.20, n.4, p. 874-907, oct.1995.

GODOY, A. S. Refletindo sobre critérios de qualidade da pesquisa qualitativa. Gestão.Org - Revista Eletrônica de Gestão Organizacional, Recife, PE, v. 3, n. 2, p. 80-89, maio/ago. 2005.

HOPWOOD, M.; MELLOR, M.; OBRIEN, G. Sustainable development: mapping different approaches. Sustainable Development, v.13, n.1, p. 38-52, 2005.

LEE, S. Dynamic and multidimensional measurement of product-service system (PSS) sustainability: a triple bottom line (TBL)-based system dynamics approach. Journal of Cleaner Production, v. 32, p. 173-182, 2012.

MARCONI, M. A.; LAKATOS, E. M. Metodologia científica. 5. ed. São Paulo: Atlas, 2010.

MUNCK, L.; BANSI, A.C.; GALLELLI-DIAS, B.; CELLA-de-OLIVEIRA, F.A. Em busca da sustentabilidade organizacional: a proposição de um framework. Revista Alcance (Online), Santa Catarina, v.20, n.4, p.460-477, 2013. 
MUNCK, L. Gestão da sustentabilidade nas organizações: um novo agir frente à lógica das competências. São Paulo: Cengage Learning. 2013.

NOSSA, Valcemiro; RODRIGUES, Victor Rangel Santos; NOSSA, Silvania Neris. O que se tem pesquisado sobre sustentabilidade empresarial e sua evidenciação? Revista de Educação e Pesquisa em Contabilidade, Brasília, DF, v. 11, p. 87-105, 2017.

OLIVEIRA, Luzia Avance de; OLIVEIRA, Edevamilton de Lima. A mulher no mercado de trabalho: algumas reflexões. Revista Eletrônica da Faculdade de Alta Floresta, Mato Grosso, v. 8, n. 1, p. 17-27, 2019.

PAZINI, M. H.; STEFANO, S. R.; FERREIRA, A.; SCHMIDT, L. P. Gestão de resíduos sólidos urbanos em Guarapuava-Paraná. Ambiência, Paraná, v. 15, n.1, p. 94-111, 2019.

QUENTAL, N.; LOURENÇO, J. M.; SILVA, F. N. Sustainability: characteristics and scientific roots. Environ. Dev. Sustain., v.13, p.257-276, 2011.

RICARDO, Veronica Silva; BARCELLOS, Sabrina Sobrinho; BORTOLON, Patrícia Maria. Relatório de Sustentabilidade ou Relato Integrado das empresas listadas na BM\&FBovespa: Fatores determinantes de divulgação. Revista de Gestão Social e Ambiental, São Paulo, v. 11, n. 1, p. 90, 2017.

SACHS, I. Desenvolvimento: includente, sustentável e sustentado. Rio de Janeiro: Garamond, 2008.

STEFANO, S. R.; TEIXEIRA, A, G. Desenvolvimento sustentável nas organizações: programas do banco do Brasil. Revista Competitividade e Sustentabilidade ComSus, Cascavel, PR, v.1, n.1, p. 46-61, 2014.

VALADÃO JÚNIOR, Valdir Machado et al. Sustentabilidade como um valor organizacional: o caso de um instituto federal. Amazônia, Organizações e Sustentabilidade, Belém, PA, v. 6, n. 2, 2017.

WU, Q.; HE, Q.; DUAN, Y. Explicating dynamic capabilities for corporate sustainability. EuroMed Journal of Business, Bingley, v. 8, n. 3, p. 255-272, 2013. 